Teble of Free Lines in Angströn's Soldr Spectrum awhich may be attributed to Oxygen.

\begin{tabular}{|c|c|c|}
\hline $\begin{array}{l}\text { Draper's electric } \\
\text { spectrum of oxygen. }\end{array}$ & $\begin{array}{l}\text { Draper's solar } \\
\text { spectrum. }\end{array}$ & $\begin{array}{l}\text { Ångström's solar } \\
\text { spectruna. }\end{array}$ \\
\hline $\begin{array}{l}4132^{\circ} \cdot 90^{5} \\
4155^{\circ} \cdot 75^{4} \\
4254^{4} \cdot 50^{3} \\
4303^{\circ} \cdot 00^{4} \\
4316 \cdot 50^{8} \\
4348 \cdot 30^{10} \\
4394.50^{4} \\
45955^{10} \\
464.15^{10} \\
4661.50^{10}\end{array}$ & $\begin{array}{l}4133^{\circ} 00^{5} \\
4155^{\circ} \cdot 60^{1} \\
4254^{\circ} \cdot 30^{1} \\
4303 \cdot 00^{5} \\
4316 \cdot 60^{2} \\
4348 \cdot 20^{2} \\
4394^{\circ} \cdot 50^{3} \\
4595^{\circ} \cdot 40^{3} \\
4648 \cdot 15^{4} \\
4661 \cdot 50^{-4}\end{array}$ & $\begin{array}{l}4133^{\cdot} \cdot 20^{2} \\
4155^{\circ} \cdot 80^{2} \\
4254^{\cdot} \cdot 55^{3} \\
4303 \cdot 00^{2} \\
4316 \cdot 50^{2} \\
4347 \cdot 95^{1} \\
4394 \cdot 45^{2} \\
4595^{\circ} \cdot 20^{2} \\
4640^{4} \cdot 75^{4} \\
466 \times \cdot 70^{2}\end{array}$ \\
\hline
\end{tabular}

The subjects presented in this communication may be briefly summed up as follows:-

I. The resort to the process of reflection in producing and photographing solar spectra, and thereby avoiding certain errors, and the employment of the silvered surface itself of a glass grating.

2. The extension of the measurement of oxygen lines into the ultra-violet region.

3. The mensirement in the region of less refrangibility than $\mathrm{H}$, of lines of oxygen not heretofore recorded, and the use of projection as a method of measurement.

4. The establishment of a close relationship in position between certain lines in the solar spectrum and the lines of oxyoren; the slight differences that exist being assignable to the experimental difficulties in the way of making accurate measures of the oxygen lines, and falling within the limits of error of experiment.

5. The evolution of the fact that the lines of the solar spectrum which appear to correspond to the lines of oxygen are weak, or fainf, and show that that gas possesses a feeble absorbent power when compared with metallic vapours or gases iike $\mathrm{H}, \mathrm{Fe}, \mathrm{Ca}$.

6. The demonstration that in Angström's chart there are many lines not assignable to any elementary body, and that these lines occupy very closely the positions of certain oxygen lines.

7. The suggestion that the proof of the presence in the solar envelopes of oxygen, and other substances giving faint lines, is a problem not to be solved by the comparison of two spectra of small dispersion. The solar spectrum in certain parts is so crowded with lines presenting all kinds of details, that the only satisfactory way is to make measures of the positions of these lines on a large scale, and as truly as possible, and then compare with these the most accurate measures of oxygen lines that can be made.

\section{CYON'S RESEARCHES ON THE EAR T.}

\section{II.}

$\mathrm{H}^{\wedge}$ VING now described, at what we hope onr readers will not consider inordinate length, the history of the subject up to the time when Dr. de Cyon commenced his second series of experiments, a history which he gives in the frrst part of his thesis in a very clear and impartial manner, we shall now give a short in a very clear new matter contained in the second part. This may be arranged under two heads-( $\mathrm{r}$ ) experiments undertaken chiefly with the view of testing the kinetic theory, and (2) the statement of his own theory and arguments in support of it.

The experiments have obviously been made with extraordinary care and skill. Dr. de Cyon succeeded in producing the lesions which he intended to produce, without injuring any other part, and in most cases with scarcely any loss of blood; we can thus observe the effects of any particular operation without the slightest complication from concurrent injury:or infiammation of the cerebellum. He has established in the most convincing way, (I) the fact observed by Flourens that the movements of the head always take place "in the plane of the divided canal," or,

I Recherches expérimentales sur les Fonctions des Canaux semi-circuhaires et sur leur Rôle dans la Formation de la Notion de l'Espace. Par Elie de as we should express it, about an axis at right angles to that plane. (2) That the movements are much more violent, and that the loss of equilibrium is much more persistent, when the corresponding canals of both sides are cut, than when one only, or two dissimilar canais are divided. (3) That when all six canals are destroyed very violent and complex convulsions occur and continue for several days. If the animal survive this stage it gradually attains a condition in which its movements are effected with great deliberation, and in which the sense of sight is absolutely necessary to enable it to direct itself. These experiments were made upon pigeons, upon rabbits, and upon lampreys, the latter animals being especially interesting as possessing only four canals, two on each side.

So far, the results of the new experiments confirm and render more precise the knowledge derived from previous investigations, and they are in perfect accordance with the kinetic theory. One point, however, requires special notice.

Dr. de Cyon points out that the first movement made by an animal on the section of a canal, takes place in a direction "from the divided canal." It is not quite easy to make out the precise meaning of this phrase. It may, and probably does mean, that when the left horizontal canal is cut the pigeon moves its beak to the right; but, as the operator is at the back of the bird, it may also mean that the back of the head moves to the right and away from the divided canal. Judging, however, from the experiments upon the vertical canals, it is most probable that Dr. de Cyon means that the first movement takes place in such a manner that the ampulla of the divided canal precedes the canal. If this be the case, and if, as seems reasonable, we assume that the first effect of the division is stimulation and not paralysis, and that the movement is a compensatory one-that is, the result of an effort to preserve the same position-we are forced to the conclusion that the canal is affected by a rotation in which the ampulla follows the canal, contrary to the view somewhat hesitatingly expressed by Brown and Mach.

Dr. de Cyon has, however, made several experiments, the results of which cannot so easily be harmonised with the kinetic theory. These experiments were made expressly to test the truth of this theory, and in his opinion their results render it untenable. As Mach holds that change of pressure in the ampulla excites the ampullary nerves and produces a sensation of rotation, Dr. de Cyon devised and executed a series of experiments so arranged that the pressure in the ampulla should be changed, without injury to the membranous canals. $\quad 1$. He opened the bony canal and allowed the perilymph to escape. 2. He opened the atricle and allowed the endolymph to escape, and observed that the whole membranous labyrinth collapsed. 3. He introduced into the space containing the perilymph small rods of dried laminaria; these rods slowly swelled by imbibing moisture, and must have considerably increased the pressure in the interior of the cavity. In none of these cases did he observe any trace of the Flourens phenomena. 4. He replaced the perilymph by a lukewarm solution of gelatine, which solidified, and inclosed the membranous labyrinth in an approximately rigid case. Still no Flourens phenomena were observed, but these at once occurred on pricking the membranous canals through the solid gelatine.

Dr. de Cyon further mentions as an argument against Mach's view, the fact that periodic changes of pressure occur in the contents of the labyrinth, synchronous with the heart's beat, and evidently comnected with the change of arterial pressure. This, he thinks should, on Mach's hypothesis, produce irritation of the nerves and sensation. It must, however, be observed, that this change of presstre is produced simultaneously in all the six ampullae, and that therefore the resultant rotation perceived would be zero.

But by far the most important evidence in opposition to the linetic theory is derived from the section of the whole anditory nerve. $\mathrm{D}$ : de Cyon succeeded in performing this operation without serious injury to any other part, and found that rabbits, in which both of the auditory nerves had been divided, and in which, therefore, all nervous connection between the semicircular canals and the brain had been cut off, showed, after being subjected to rotation, the same symptoms of vertigo being sul normal rabits. It is unfortwmet that Dr. de Cyon has not given further details of this most important experiment.

External imitations which, when small, are perceived only by the organs specially fitted for their perception, as a rule act, the organs specially fitted for then intense, upon other organs. Thus a feeble sound can 
only be heard, a small quantity of an odoriferous substance can only be smelled, a dilute solution of a sapid substance can only be tasted, but a very loud sound can be felt by producing vibrations sensible to the nerves of the skin; ammonia gas attacks the mucous membrane of the nose, and mustard bites the tongue. These are not sensations of hearing, smell, or taste, but they are sensations produced by external irritations which, when feebler, are perceptible by these special senses only. It is not, then, unreasonable to suppose that sudden and violent changes of rate of rotation should be perceived by the shock communicated to all the sof and movable parts of the body, although slighter changes may be perceptible only by the special organ of the sense of rotation. The experiment just mentioned is undoubtedly a crucial one, but, in order to obtain from it a decisive answer, it would be necessary to make a series of comparative trials, with varied rates of rotation, upon normal rabbits, and upon rabbits whose auditory nerves had been divided; if no difference is observed, even with moderate change of rate, the kinetic theory must be abandoned.

A great deal of valuable information might be obtained by care fully testing the delicacy and accuracy of the sense of rotation in deaf-mutes. Many deaf-mutes have not only the cochlea, but the whole internal ear, destroyed; if, then, the inmates of deaf and dumb establishments were systematically tested by means of such experiments as Mach and Brown made upon themselves, experiments which would, no doubt, greatly interest and amuse them, and if the condition of the internal ear were, in each case of post-mortem examination of a deaf-mute, accurately noted, we should soon obtain a mass of information which would do more to clear up the relation between the sense of rotation and the semicircular canals than any number of experiments on animals unable to describe to us their sensations.

We cannot pass from this criticism of the kinetic theory without noticing a passage in Dr. de Cyon's thesis which seems to show that he has not fully appreciated the bearing of this theory :- "Quelques mots seulement pour mieux faire ressortir l'invraisemblance d priori de la thérie de MM. Mach, Crum Brown et d'autres. Comment admettre que les canaux semicirculaires servent à nous informer sur la rotation de la tête, quand rous voyons les mêmes organes paríaitement bien développés chez les animaux qui, comme les grenouilles ou les poissons, ont la tête presque immobile et qui d'ailleurs, pas plus que les autres animatux, n'exécutent pas habituellement des mouvements de rotation?

"Pourquoi justement la présence d'un organe des sens pour un mouvement peu habituel et pas pour beaucoup d'autres, pour les mouvements que les animaux exécutent continuellement?" P. 47 .

No doubt a frog or a fish cannot move its head freely without at the same time moving its body, but head and body together move and perform frequent and rapid rotations. Whenever a fish or other animal changes the direction of its motion, rotation takes place, and a knowledge of the amount and of the axis of this rotation is necessary if the animal is to retain any sense of its orientation. Of all animals a fish, moving and turning with great rapidity and sharpness in a dense medium often affected by complicated currents, seems to have most need of such an organ which serves the same purpose as a ship's compass, an instrument surely not useless because a ship is rigid and does not habitually perform movements of rotation.

We have already alluded to some of the phenomena of optical vertigo. This subject is discussed at considerable length by Dr. de Cyon, and it is therefore right that we should here explain somewhat fully the opinions held in reference to it by various experimentalists.

The phenomena themselves are, in the main, well known. If we rotate about a vertical axis either actively (that is turning ourselves) or passively (that is being turned round on a movable chair or platform by an assistant) we are at first fully aware that we are turning and that external objects are at rest; gradually external objects seem to move round us in a sense opposite to that of our real motion. If at this stage we stop we not only feel that we are being turned round in the opposite sense to that of the previous real motion, but we see, or think we see, external objects turning round. These two imaginary rotations, viz., that of our body which we feel, and that of external objects which we see, take place about the same axis, in the same sense and at the same rate. The axis is parallel to the line in the head which was the axis of the original real rotation, and the sense is, as already explained, contrary to that of the original

rotation. These facts are well known and were fully described by Darwin in the "Zoonomia" and by Purkinje. Another phenomenon closely connected with them was first noticed by Purkinje, and has since been investigated by Breuer and by de Cyon. When a real rotation of the body talies place the eyes do not at first perfectly follow the movemes place the eyes While the head moves uniformly the movement of the head. in the diagram, Fig. 3, where the abscisse move by jerks. Thus, ordinates the angle described, the straight line $a b$ represent the continuous rotatory motion of the head and the roted the discontinuous motion of the eye.

Here it will be seen that the eye looks in a fixed direction for a short time, represented by one of the horizontal portions of the dotted line $a b$, and then very quickly follows the motion of the head, remains fixed for another short time, and so on. After the rotation has continued for some time the motion of the eye gradually changes to that represented hy the dotted line $c d$ in Fig. 4. The eye now never remains fixed, but moves for a short time more slowly than the head, then quickly makes up to it, then falls behind, and so on. At last the discontinuity of the motion of the eye disappears, and the eye and head move together.

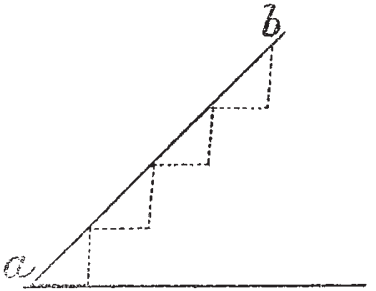

Fing.3.

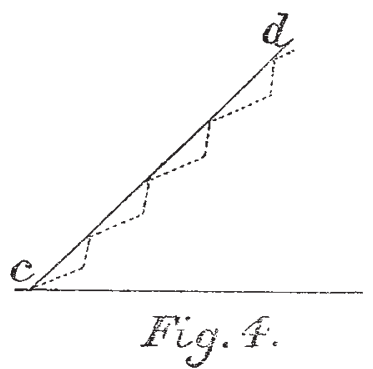

If now the rotation of the head be stopped (of course the body stops also) the discontinuous movements of the eyeballs recommence. They may now be represented by the dotted line in Fig. 5 .

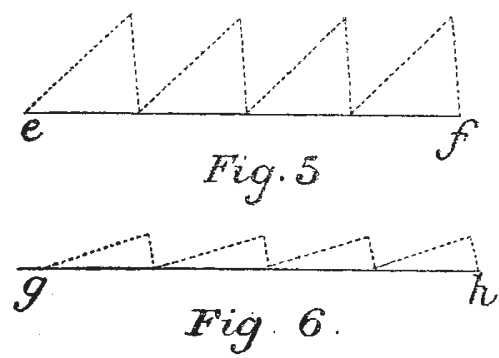

The intermittent motion of the eyes gradually becomes less, passing through a condition such as that shown by the dotted line in Fig. 6, and at last ceases. The consideration of these oscillatory motions is greatly simplified if we draw diagrams similar to the above, but in which $\frac{d y}{d x}$ is made proportional to the apparent rate of rotation, that is, to the rate of rotation as perceived by the observer, instead of to the real rate as mea. sured or inferred from external observations.

The apparent motion of the head and of the eyeballs is shown in Fig. 7 when uniform real rotation is kept up until it ceases to be perceived, and is then suddenly stopped. ${ }^{1}$ The accented letters $a^{\prime}, b^{\prime}, \& c$. , correspond to $a, b$, \&c., in Figs. 3, 4, 5, and 6.

We now see what is the real nature of the oscillatory movements. The eye remains for a short time in an apparently fixed

In order to represent accurately the phenomena, the oscillations should be much more numerous and of course smaller. As five or six complete turns are required before all sense of rotation is abolished, and as Dr. Breur finds at leaste the should be at Breuer finds at least ten oscillations in one complete turn, there should we least fifty between $a^{\prime}$ and $e^{\prime}$. These could not be represented without making the figure either very large or very indistinct. Such diagrams ar not used by any of the physiologists who have investigated the subject, and must not be interpreted too rigidly, as both the duration and the extent of generalnatu" of the phenomena sufficiently for cur purpose. 
direction, that is, in a direction which the experimenter, judging them as the effect, of the visual vertigo. The Iatter opinion from his sensation of rotation, concludes to be fixed, then rapidly returns to its original position relatively to the head, again for a short time looks in an apparently fixed direction, and so on.

Some physiologists have considered the e oscillatory movenents as the cause; others-and notably Dr. de Cyon-regard

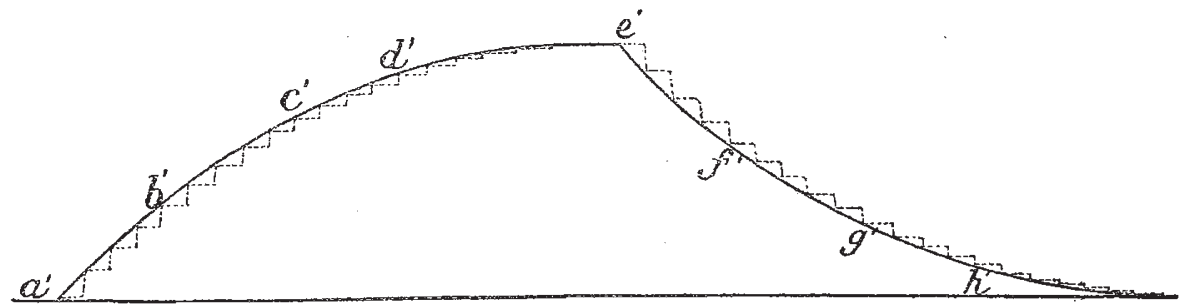

Fig.7.

tively to his head; he sees tbat external objects are at rest relatively to his head; and he concludes that, as his head is turning round, his body, his chair, and all external objects must be tuming round also-his eyes oscillate precisely as they would do if all these imaginary rotations were real.

Similar oscillatory movements of the eyeballs are described by Dr. de Cyon as resulting from the section or mechanical irritation of the semicircular canals in rabbits, and are by him referred to reflex action dependent on intimate anatomical con. nection between the roots of the nerves of the ampulla and those of the motor nerves of the eye. The points of chief importance noticed by him are :-

I. At the moment of irritation the spasm of the muscles of the eyeballs has a tetanic character; immediately afterwards the oscillations commence, and last for a variable time, depending on the intensity of the irritation, and rarely exceeding halfan-hour. The frequency of the oscillations varies from 20 to 150 per minute.

2. The direction of the oscillations depends on the particular canal cut or irritated. Dr. de Cyon deseribes, somewhat minutely, the direction in each case, but states that he finds it difficult, on account of the peculiar position of the eyes in the rabbit, to give a precise determination of these directions. From his descriptions we can, however, gather, with considerable probability, that the eyeballs oscillate about an axis perpendicular to the plane of the divided or irritated canal.

3. The oscillations, caused by the irritation or section of any one canal, cease when the opposite auditory nerve is divided; new irritations of the canal then produce only tetanic contractions.

The direction of the initial tetanic spasm is given by Dr. de Cyon, and appears to coincide with what we should expect if rotation with the ampulla preceding be supposed to excite the ampullary nerves; this result leads to the suspicion that we may have misinterpreted the author's account of the initial movement of the head on section of one canal in the pigeon.

We have now only to state and examine Dr. de Cyon's theory of the function of the canals and of the part which they take in the formation of the idea of space.

This theory is stated in a very general form, and it is difficult by a single quotation to do full justice to it. We quote, however, two passages in which it is distinctly enunciated, and refer the reader for its full discussion to the thesis itself :-

"Les canaux semi-circulaires sont les organes périphériques du sens de l'espace; c'est-à-dire que les sensations provoquées par l'excitation des terminaisons nerveuses dans les ampoules de ces canaux servent à former nos notions sur les trois dimensions de l'espace. Les sensations de chaque canal correspondent à une de ces dimensions.

"A l'aide de ces sensations, il peut se former dans notre cervean la représentation d'un espace idéal sur lequel seront rapportées toutes les perceptions de nos autres sens qui concernent la disposition des objets qui nous entourent et la position de notre corps parmi ces objets."-P. 64

"La disposition des nerfs, dans trois plans perpendiculairs l'un à l'autre, se prête à merveille pour une pareille fonction. Nous pouvons tres bien nous figurer comment les sensations d'etendue, dans trois plans, dont la disposition, chez tous les vertébrés, répond exactement alx trọis co-ordomées de l'espace, seems the more reasonable; and indeed both visual and tactile vertigo seem to be matters of judgment rather than of sensation. When the real rotation stops the experimenter perceives, by his sense of rotation that his head is turning round; he feels that his body and the chair on which he sits are at rest rela-

peuvent être ntilisées par notre intelligence pour la construction d'une notion de l'espace.

"Je dirais plus : aucun autre sens ne présente une relation aussi facile à saisir entre la représentation et la sensation, que le sens d'espace, d'après ma manière de voir."-P. 73.

This is not inconsistent with the kinetic theory as explained above. The difference is that that theory does, and Dr. de Cyon's does not, explain what the sensations of the canals are and how they contribute to our ideas of direction or orientation in reference to three rectangular axes.

There are two ways in which we may investigate the action of an organ of sense :-We may examine and compare the information we obtain by means of the sense under a great variety of conditions; this is the way in which our knowledge of physiological optics has been chiefly obtained: or we may study the effects of injuries of the organ, either occurring naturally or intentionally produced. A detailed theory has, in the case before us, been sooner attained by the first of these ways than by the second. This theory must be tested by experiments carried ont in every appropriate way, and, if necessary, must be modified in accordance with their results. We may thus expect to obtain a knowledge of the mechanism of the sense of orientation as complete as that which we have of the mechanism of the sense of sight. Dr. de Cyon's thesis contains the record of a very considerable step in this direction.

\section{Alex. Crum Brown}

\section{UNIVERSITY AND EDUCATIONAL INTELLIGENCE}

The President and Fellows of St. John's College, Oxford have just passed the following resolution nem. com. : "That independently of the granting of Fellowships for the assistance of research, the college shall from time to time make money grants for that purpose." The granting of Fellowships alludes to a clause in the new Statutes which has just been drafted, in which a Fellowship is set apart for this purpose.

PROF. HUXLEY will lecture at a general meeting of the Working Men's College, Upper Kennington Lane, to be held on the $24^{\text {th }}$, at 8.30 P.M. , to inaugurate the new premises of the College, near Vauxhall Station, one part of which bas been fitted up as a chemical laboratory, with all the appliances needed for the study of practical chemistry.

THE New South Wales correspondent of the Colonies states that, in consideration of the necessity which is now felt for extending the curriculum of Sydney University and augmenting its teaching powers, the Colonial Government have consented to ask Parliament for an additional annual grant of $5,0 \mathrm{col}$. This will enable the Senate to make the following additions to the present course of study:-(I) Mental philosophy, law, history, and English literature ; (2) all the education necessary for the medical profession; (3) a complete course of natural philosophy, coupled with mechanics and engineering; (4) the addition of organic chemistry and metallurgy to the chemical school; and (5) biology, including animal and vegetable physiology. The Senate will also be in a position to establish a faculty of science, and to confer the degrees of Bachelor and Doctor of Science, and also degrees in medicine, on those who have received their education in Sydney. 